The Canadian Journal of Higher Education, Vol. XXIII-1, 1993

La revue canadienne d'enseignement supérieur, Vol. XXIII-1, 1993

\title{
The University in the 1990s: Crisis or Predicament?
}

\author{
W. M. SIBLEY*
}

\begin{abstract}
The financial difficulties which our universities are currently encountering are not without precedent, as a brief retrospective look at conditions in the 1930s will attest. However, the "decision space" in which we must operate today is far more circumscribed than at any time in the past. External constraints continue to increase in number and severity; the contemporary academic culture has greatly weakened old institutional values and identities; and governance structures have become inordinately complex, cumbersome, and ill-adapted to deal with existing realities. In these circumstances, strident demands for "greater accountability" and "stronger leadership" cannot really be met. It is imperative that we not only address certain pressing problems but also identify several genuine system contradictions, which cannot be evaded and sooner or later must be resolved. Any credible agenda for renewal must be based on new paradigms of participation and models of governance, that will enable us to create patterns of decision-making far more suited to cope with emerging realities than the outmoded forms embedded in our current systems.
\end{abstract}

\section{Résumé}

Les problèmes financiers auxquels les universités sont présentement confrontées ne sont pas nouveaux comme une analyse rétrospective de la situation dans les années trente le démontrera. Cependant, "l'espace de décision" dans lequel chacun doit maintenant opérer est beaucoup plus

* Special Adviser to the President, University of Lethbridge 
circonscrit qu'il ne l'était dans le passé. Les contraintes provenant de l'externe augmentent continuellement en nombre et en intensité; la culture académique contemporaine a affaibli l'identité et les valeurs institutionnelles traditionnelles; et les structures de décision sont devenues excessivement complexes, lourdes et inadapteees aux réalités actuelles. Dans ces conditions, les demandes pressantes visant le renforcement des mécanismes de reddition de compte et le leadership ne peuvent être satisfaites. Il devient donc urgent de ne pas répondre seulement aux problèmes les plus pressants mais aussi d'identifier les contradictions systémiques qui tôt ou tard devront être confrontées et corrigées. Tout renouvellement, s'il veut être crédible, devra être axé sur de nouveaux modèles de participation et de gestion permettant de créer des modes nouveaux de décision mieux adaptés aux réalités modernes que les modèles traditionnels sur lesquels reposent toujours nos systèmes actuels.

\section{A Predicament Revisited}

Sixty years ago this month, the National Conference of Canadian Universities (an organizational ancestor, at several removes, of the present Association of Universities and Colleges of Canada) met in Ottawa for the annual gathering of heads of institutions.' The record of the meeting pays due tribute to "the jovial hospitality" of the University of Ottawa, "which the members of the...Conference associate with this institution." Funding matters were not agenda items at this or other sessions of the NCCU; rather, time was devoted almost exclusively to solemn and learned debate by the presidents and senior deans on matters of immediate or long-range academic import. For example, there were repeated expressions of concern over the poor quality of student writing. A paper in this vein, delivered at the 1927 Conference, bore the title: "The Weakness in English of Large Numbers of Graduates and Undergraduates." The quality of secondary education was a frequent topic: in 1930 anxious discussion was devoted to the question, "How Can First Class Honour Graduates be Induced to Make Teaching a Life Work?" There were frequent references to the serious problem of attrition in Canadian high schools. "Is Canadian Education Fulfilling its Purpose?" and "Is the Present High School Curriculum in Canada Adequate to the General Needs?" were additional questions for debate at one or another sessions of the old Conference. ${ }^{2}$ Evidently, some academic concerns are hardy perennials; only the language of discussion changes.

Underneath this tranquil surface, however, university affairs were in a far from satisfactory state. Most universities were undergoing a severe financial trauma. Indeed, in the face of this crisis the 1932 Executive of the NCCU 
decided unanimously on two relevant courses of action. On account of what were tersely called "financial difficulties," it was decided not to hold any meeting in 1933: the plain truth was that some universities were hard pressed to find the wherewithal to send a delegation to Ottawa. A second measure was also adopted, in view of the fact that the balance sheet of the Conference was in such sound condition. Expenditures to the extent of $\$ 764.71$ had all been met, and the association's bank and trust accounts stood at the healthy figure of $\$ 1,363.50$. It was therefore further resolved that for the next year payment of annual dues would be suspended. The dues ranged from a low of $\$ 10$ a year for most institutions, to $\$ 50$ for several larger places. For some unexplained reason, the then relatively small University of Alberta paid dues of $\$ 60-\$ 10$ more than Toronto. (Do I not rightly see here yet another item in the long list of outrages against the West?)

For several good reasons, no one from the University of Manitoba could attend the 1932 meeting. Over a two-year period, its provincial grant would be cut exactly in half. Slashes in salary up to 25 percent or more were being imposed and tuition fees were in process of being raised to unheard of levels. In addition, nearly all the University's endowment was lost through fraudulence on the part of the chairman of its Board. The absolute amount was small by today's standards but relatively it was very great, being equal to no less than four times the 1933-34 grant. Manitoba was saved only by the grim determination and deep loyalty of faculty and staff, students and alumni, and the resolute action of a group of prominent citizens. Other universities both east and west were undergoing similar hardships and privations, as their histories show. The president of Mount Allison, for instance, expressed the fervent hope that he could at least save the positions of his department heads. The situation was occasionally so desperate that in several instances closure was being mooted, and in the most serious terms. Even the far western institution, the University of British Columbia, was saved only by a dramatic student appeal to government, a move which issued in a grant increase of $\$ 25,000$ - just half the revenue which the second of two very sharp fee increases would produce, but which in concert with those increases was sufficient to ensure the university's survival.

There are several lessons to be learned from recollection of this history. One is that Hard Times came-and Hard Times can come again. A second reflection relates to resources. Institutions that came through this period of trial were marked by a very strong identity and distinctive traditions, and hence could draw upon deep wells of institutional loyalty and commitment. A third reflection is that the governing structures under which they operated proved 
adequate to the severe crisis they were undergoing. Those institutional forms carried them not only through the depression but through the subsequent stresses of the war years as well.

Although some of the questions confronting us today are similar, the answers may well be different. While no one can predict with certainty our fiscal future, the outlook is far from promising. At a meeting of the AUCC in March of 1992 the keynote speaker, Mr. Jeffrey Simpson of The Globe and Mail, remarked that we had all been engaged in "fiscal folly" for at least half a generation, and that it surely would take us at least that long to recover. No one ventured to disagree with that prognosis. In other words, for the rest of the decade our universities are likely to be under severe financial pressures. But what resources do we have at our disposal to meet that stress? And are our forms of governance and management adequate, or do we face the necessity of some fundamental restructuring? We are certainly in what my O.E.D. terms a predicament - namely, "an unpleasant, trying or dangerous condition." How far this will also prove to be a "crisis" remains to be seen, but present omens are not auspicious.

The predicament may be illuminated by examining the conditions under which decision making and planning in the contemporary university take place. ${ }^{3}$ Let us locate the decision maker in a "decision space," the contours and area of which are determined by several sets of factors. Three major sets of forces constrain our decision space and therefore limit our freedom to plan and decide: (1) forces in the external environment; (2) factors inherent in the academic culture; and (3) constraints arising from our current management and governance structures.

\section{External Constraints}

That demands upon the university have never been greater or more numerous than today is a proposition not in need of much defence. In the national as well as the provincial interest, we are being urged to maintain and even increase accessibility to higher education. A never-ceasing stream of legislation imposes upon us an entire array of new demands, for instance in the form of employment equity, with its many dimensions and difficult problems of implementation; or in new and ever more costly health and safety measures. Rarely, if ever, is adequate compensation provided for such additional burdens. We typically are constrained to provide employee assistance and sexual harassment offices as well as enlarged student counselling services. Regardless of cost, we are also expected to show leadership in areas of environmental concern. Collective bargaining 
regimes of one type or another are mandated either by legislation or by contractual arrangements arrived at in more favourable economic conditions than those we are now facing. There are pressures for ever greater participation in decision making at all levels of our operation. At the same time as decision making thereby becomes more and more diffused, the contradictory cry goes up for still greater accountability. Grievances flourish in even the least adversarial university cultures; "creeping legalism," the unwelcome offspring of unionization, leads to ever more frequent and more expensive recourse to litigation. We are enjoined to improve the quality of our graduates, and simultaneously to engage in productive research in areas of social relevance or economic need. Income is only marginally under our control, and most costs are not in the slightest degree at our discretion: yet we are expected or required not to incur an operating deficit. Above all, we are urged to be immediately responsive to new needs and demands, especially in the way of serving as a spearhead in the drive for a more competitive economy. All such pressures enormously constrain our planning and decision space, affecting as they do fundamental realities and perceptions about what can and cannot be done. ${ }^{4}$

\section{The Academic Culture}

Members of a university faculty have always belonged to two orders: that of the discipline or field of study in which they make their career, and that of the institution in which they are located. Universities are thus examples par excellence of a matrix organization. A major change, however, has come over the university scene in the last generation. That change has been a marked increase in the dominance of the role played by the discipline in the life and work of the individual, as contrasted with the place occupied by the institution or (in the terminology of the American analyst Burton Clark) "the enterprise." With the rapid and continuing advances in knowledge over the past few decades, the disciplines have come to assume clear primacy over the enterprise, owing to the great success they have enjoyed in the front-line tasks of acquiring and disseminating new knowledge.

By far the greatest portion of the professional life of academics is now shaped by adherence to practices and norms established by the "guilds" to which they severally belong, whatever their chosen line of disciplinary endeavour. In addition to their "vertical" membership in a particular university department, academics participate in this "lateral" membership in formal and informal professional associations outside their institution. Performance according to the norms of the discipline is of overwhelming importance to one's career 
prospects. In this respect the academic world differs radically from the corporate. Academics belong to an "invisible college," which is governed by its own paradigm of knowledge and prescribes its own ideal curriculum. In subtle fashion that "invisible curriculum" will tend to displace the educational goals to which the institutional curriculum was once directed. Identity is always founded on difference: as universities come more and more to resemble one another, both institutional identity and hence institutional loyalty are necessarily attenuated.

Other related changes also occur. Academic organizations are increasingly fractured by expertise, rather than unified by it. Concentration on the "stuff" of knowledge is what academics have in common; but nowadays (as Clark puts it) what they have least in common is common knowledge. The disciplines fly apart from one another, and at ever increasing velocity. Moreover, the university becomes "bottom heavy." The "action" and excitement are more and more to be found at the departmental level, where the experts reign supreme over their own disciplinary turf. Faculty consequently become progressively less interested in and less competent even to understand matters of broad university policy. It is not accidental that the passionate and exciting senate debates of the $1960 \mathrm{~s}$, in which involvement was very general, seem no longer to characterize the universities of the 1990s. As one participant of long experience put it at the March, 1992 AUCC meeting, "the one brief shining moment of the 1960s" has disappeared, and for the most part, he felt, senate discussion now wanders in a mere wilderness. $^{3}$

One further characteristic of the contemporary academic culture is that the old notion of the institution is increasingly displaced by that of a mere organization. Members of an institution, in the classical sense of the word, hold wellrecognized offices, where an office entails the concept of a duty or charge that falls to someone or is assigned as a matter of some type of obligation. It signifies a trust or a fiduciary status. In the traditional "college," for instance, the trust is seen with especial clarity in terms of the relationship of faculty to students. Students were wards, yet also junior members of the college who were being initiated into the community of learning. In such a setting, the old collegial claim made by faculty, that "we are the university," made good sense. The gown of the professor, like the gown of the cleric or the lawyer, signified a position of eminence and trust.

More and more frequently, however, modern academics have come to think of themselves simply as members of an organization. Gowns have long since disappeared, as has also the high state of esteem in which the professoriate used 
to be held by the public at large. By some academics, the status of mere employee - at one time vigorously and indignantly repudiated-is even insisted upon, as a kind of proletarian badge of honour. In the mass, students are sometimes seen not as wards but as no more than clients-and vulnerable clients at that. The contrast is seen with stark clarity when faculty elect to strike: their power comes directly from their ability to inflict injury upon students, and about this some of them are remarkably frank. In such a state "collegiality" seems now to mean little more than a collective solidarity in the defence of common interests, or the principle of peer decisions in matters of professional competence.

\section{Governance and Management Structures}

Still a third set of forces acting to shape the size and contours of our decision space, and thus to influence the scope of our action, is to be found in our structures of governance and management. ${ }^{6}$ On the side of the former, most universities operate on the bicameral system, the two senior bodies being an academically dominated council or (to employ usual terminology) "senate," and the second a board of trustees or governors. It is not an easy matter to specify the relationship between these two bodies. Senates are in charge of something called "academic governance;" but since decisions in that sphere clearly have economic consequences and therefore intrude upon the sphere of "management," there is in fact an uneasy juxtaposition and mingling of authority, regardless of what university acts or individual charters may say. Nominally, boards generally have plenary powers in reserve; but in reality some kind of consensus must always be effected, a task which puts a burden of great weight upon the shoulders of the president.

Over the past two decades, academics have in general acquired a two-fold influence over many decisions: one through their control of senate and the second through collective bargaining arrangements, whether these exist within the structure of certified unions or in non-certified associations. Even in the latter case (as in Alberta), faculty handbooks may and do contain immensely detailed rules governing appointments, merit increments, dismissal procedures, handling of grievances, stipulations regarding the evaluation of teaching, and the like. In some institutions the board is powerless even to declare a financial exigency independently of procedures (often lengthy, disputatious, and costly) laid down in such agreements; and apparently no Canadian university has yet been able to declare such an exigency. One wonders how long that situation, embracing such a conflict of interest, can continue. In any event, the existence of such 
contractual structures practically constitutes a "third chamber" operating alongside board and senate. It remains to be seen whether such a complicated "three body" system can survive years of intense pressure. (There is as yet, I understand, no analytical solution to "the three body problem" in physics, and I predict that there will be none in academe either.)

One very important further aspect of our structures has been the general (if not quite universal) disappearance of the department "head"-a figure whose authority, for better or worse, used to be immense. Heads have typically been replaced by a system of rotating "chairs," whose authority is often highly circumscribed by collective agreements and who may have neither the power nor the incentive to make tough judgments about their colleagues, especially when they themselves will shortly relapse into the ranks after their term is finished. The committee process yields reasonable enough verdicts about research competence; in my experience, however, it does not and cannot possibly reward the existential and personal task of teaching as much as that function deserves, so that current demands to "do something about rewarding good teaching" are not likely to get very far within existing structures.

\section{The Conditions of Accountability}

Under the joint pressure of all the above forces, the decision space which universities currently occupy has become extremely confined. One indicator of our restricted capacity to respond effectively to contemporary challenges can be seen in the issue of accountability. Current demands for greater accountability, coming chiefly from government, originate in concerns which will place increasing pressure upon our institutions, and which in part reflect the marked constraints under which governments themselves are labouring.?

At recent university conclaves, this question of accountability has emerged as a dominant theme. There is little disagreement that some constructive response is called for, but some uneasiness as to the validity of certain pressures. It is not immediately evident, for instance, who can properly define societal "need," and who rightly speaks for the public interest: one can hardly assume that in all cases it is the political party currently in power. In university circles there is considerable agreement with some of the suggestions made by Dr. Stuart Smith in his survey of Canadian higher education, namely, those which call for universities to state as clearly as they can what they are about, to find some useful ways of measuring how far they are attaining those objectives, and then to communicate the results of such intelligent self-examination both to 
government and to the public. Such efforts will be costly but are surely mandatory.

Certain other demands, however, raise difficulties. For one thing, the list of things for which some one or other thinks we should be responsible can be almost endless. Even when we group such requests under that old familiar pair of twins, Efficiency and Effectiveness, problems remain. There is not only the question of what we might reasonably be expected to do, although some framework of legitimate expectations certainly is needed. One must also ask: Just what is it to be accountable?

In the first place, if I am to be held accountable for something, I must have been the agent responsible for it. Or, if there was joint action on my part with others, then one must be able to identify the group which was responsible. Responsibility has to do with agency. Accountability, however, requires something in addition. If we are to hold some one accountable, we must be able to "call that person to account," i.e., bring home to that individual the consequences of his or her action. Accountability is about a certain power-namely, the power to reward or to impose penalties. Our forebears, for example, are responsible for much environmental pollution; but we cannot speak of holding them accountable.

It is at this point that the complex maze of university decision makingthat big, buzzing, blooming confusion-frustrates the protagonists of accountability. Over the years, for instance, many a senate has allowed courses to proliferate beyond reason, curricular requirements to become rigid or out of date, and cumbersome committee structures to flourish like the proverbial green bay tree. But whom will you hold accountable for this wasteful academic bureaucracy? The senate is formally responsible, but there is no way of visiting any benefit or disbenefit upon its members. In any case, given our fluid participation in decision making, those who did create the mess are probably long gone. The chain of accountability may formally start with the board of governors, but once it reaches the senior academic body, it breaks off. There is little more hope of enforcing accountability along the administrative chain. Not long ago a cabinet minister in Alberta called for raising the teaching load from nine to twelve hours a week. When the headship was still in place, such a directive could have been passed along and speedily implemented. But chairs do not have the powers of heads. In any event, collective agreements will nearly always have something to say about conditions of employment, which will include reference to established practices or defined work loads. Even if not, unilateral action on the part of a board is usually not an option: it can simply produce a crippling number of grievances. 
A second acid test of our operating effectiveness, in addition to accountability, would raise questions about our current capacity to engage in strategic planning. All I can say here is that our universities can indeed produce excellent master plans, incorporating many admirable objectives-all feasible under the premise of expanding resources. Under a scenario of sharply contracting resources, however, strategic planning will entail hard-headed risk-taking and tough-minded measures, such as the excision of an entire academic unit. Consensual decision-making, however, renders such actions extremely unlikely if not impossible. ${ }^{8}$

The simple truth is that over the past 25 years, we have built a most complex system of governance and management, with a vast multiplicity of centres of decision making, all the way down to individual departments and their subcommittees. Superimposed upon that structure is an inordinate complexity of regulations, violation of which may bring costly consequences. The resulting system has much more to its credit than critics will sometimes allow. But it has become enormously overloaded - often by the actions of government itself. On occasion, principles of scale have also been blithely ignored, although we have known since Aristotle that an undue increase in the scale of an organism may produce most dysfunctional consequences. Given ample resources the current system can function and indeed has functioned in a reasonably satisfactory manner. Under conditions of severe and prolonged stress, however, some critical boundary might be suddenly exceeded-a possibility about which chaos theory duly warns us.

\section{The Role of the President}

Are there any simple, clear-cut remedies for coping with the predicament we are facing? One occasionally hears the suggestion that more care must be taken in the selection and evaluation of presidents, who somehow must assume the mantle of leadership which hitherto (in the eyes of some critics) they have unfortunately disavowed. To the contrary, I am confident that the present group of presidents is as capable, effective and dedicated a set of men and women as we have ever seen. Far more thought and work go into the initial choice of a president than was the case twenty years ago. Frequent evaluation and careful review, certainly before re-appointment, are also now the norm. The problem is not "leadership." Rather, it is the extreme demand for participation and consensus in all decision-making, a trend which has destroyed all "followership."

The hard reality, unfortunately, is that of the four roles typically associated with the task of presidency, two of them-the political and the managerial- 
have assumed overwhelming proportions. In the political arena, the president has to be an engineer of consensus on a dozen fronts. He or she has to conciliate the interests and perspectives of the board, the senate, powerful deans, prestigious and independent researchers, the faculty, the students, their parents, the support staff, the alumni, the public at large, the corporate world, and the government. That is a formidable array of interest groups to appease-far more extensive, one would imagine, than the array confronted by most corporate executives. On the managerial side, the demands are endless, and made more difficult by the fact that academic goals are in any case tenuous, vague and problematic, a reality complicated further by the fact of fluidity in decision making. Little energy is left, and indeed little opportunity, for the third task, that of academic leader; or for the fourth and most demanding role of all-that of functioning as the symbolic representative of the high ideals of the university as an institution. As one of their number has remarked, frustrated presidents often feel like Gulliver among the Lilliputians: "I attempted to rise, but was not able to stir."

\section{Some System Contradictions}

Let us try to understand at a more fundamental level what is happening to our institutions. What does the future hold for them? We may obtain one reliable clue by looking for a moment at the way in which we have been "managing" our capital resources. What is immediately evident is that we have been consuming them at an alarming rate. Among the provinces Alberta, for instance, has had (until recently) by far the most generous and rational scheme of providing for plant maintenance and equipment replacement. Only one of its four universities is of venerable age. A 1991 survey, however, revealed a total deferred maintenance bill for the university system of not less than $\$ 418$ million. At a guess, the national total must be close to fifteen times that figure. No adequate relief is in sight, but, like drunkards squandering their family inheritance, we continue on our merry way into capital bankruptcy.

Things are no better on the operating side, where for some time many institutions have resorted to management by "selective attrition." As full time professors have left the system, they have often been replaced by much cheaper fleets of sessionals, or part-timers on contract, or graduate teaching assistants. Many critics would urge that this use of attrition has resulted in some appreciable decline in quality. (If great scholars no longer appear in the classroom, and their place is taken by mere apprentices, how can there not be some loss in quality?) Alternatively, there has been a diminution of access. The limitation which 
gets publicized is that which occurs when qualified students are turned away at the university's gates. The more insidious kind, the dimensions of which we have no idea at all, develops when students are "admitted" but then cannot obtain entry into desired courses, perhaps even in a formally non-quota faculty. These "internal refugees," who in some places can number in the thousands, are one major consequence of "management by attrition." But no one can be held accountable for the substantial economic waste that results, since no one's fingerprints are clearly on the decisions which deny access. Whether we diminish quality or reduce access, the fact is that we have been coping with underfunding simply by a depletion of our initial stock of human resources or a waste of present ones.

Some of the contradictions from which we are suffering are encapsulated in what has been termed "the Quality-Access-Funding triangle." We are enjoined simultaneously (1) to maintain access; (2) to maintain quality; and (3) to do so with less funding. This is an incompatible triad of principles or regulations, to which there simply is no rational solution. To be sure, at a given time in a given institution there may be some elasticity in the triangle; there may be some unnecessary operational slack. If so, boards of governors must go after it, remembering, however, that not all "slack" is unnecessary: without some reserves, any system under stress will sooner or later crash.

The QAF triangle is by no means the only such inconsistent triad or downright system contradiction. The Income-Cost-Deficit set of impossibilities is still another. Here we are prohibited from: (1) controlling our income; (2) controlling most of our costs; but (3) are enjoined never to incur a deficit. Presidents ask to be "freed" to raise income, and one can heartily endorse their plea; but it is not clear what benefits would result. Could tuition fees be sharply raised? By the time students graduate, many are already carrying an appalling burden of debt, and unless some rational form of income-contingent loan repayment scheme is instituted there will be severe limits to any income gains by this route. Corporate aid to universities will be essential, but it will be both limited and selective: corporations will not be inclined to try to haul the whole enterprise out of the swamp. On the cost side, we have already squeezed many nonpersonnel expenditures as far as we can. In fact, most of the items within this envelope, which tends to constitute about $20 \%$ of the general operating budget, wholly escape our discretion. As for the $80 \%$ or thereabouts which goes into salary and benefits, collective bargaining regimes and market pressures will jointly determine the bulk of what must be done.

In retrospect, it is clear that the main features of our present governance and management structures were laid down in the heady and profligate days of 
the 1960s. Support was not only generous-in some respects it verged on the lavish. We tacitly assumed as an operating premise that there were no limits to growth $\longrightarrow$ or at the very least, that we would be fully funded at some steady and comfortable state. But what will happen under severe and prolonged fiscal decline?

\section{What To Do Till the Doctor Comes}

The response to that question by the ablest minister of advanced education under whom I have ever served was that universities would have to undergo "either slow strangulation or radical surgery." Predictions of surgery might or might not come true, but just in case it is scheduled we might ask: What should we be doing in the meantime?

Several levels of action are thinkable. At the first level, boards of governors could look for savings. For instance, by some estimates as much as $15 \%$ of professorial time is invested in academic administration, in the operation of senates and numerous other councils. Leaner agendas, fewer meetings, smaller committees, and much more leeway for senior administrators to make necessary decisions could markedly lower current costs in this domain. Nor should we overlook the substantial overhead costs (such as secretarial time, for instance, or the time of senior administrators) associated with such resource consumption. Again, given all the marvels of modern communications, one wonders further whether we really need all the fleets of secretaries we now employ. Even the most "keyboard-challenged" amongst us are now learning to be more independent!

In some fields (to give a third example) other management efficiencies may be found. Our local board of governors, for instance, has implemented the G.A.A.P. approach ("Generally Accepted Accounting Principles") to all our ancillary operations. This is a move which may in the end not yield large savings, but at least is an excellent discipline and training exercise for all of us. If, contrary to present official policy, we find that we eventually are forced to subsidize one of these operations, we shall at least have some idea what the true costs are and just why such subsidy is necessary. Senates and faculty councils generally are going to have to learn different but appropriate forms of such costconsciousness, right down to departmental levels.

Such cost-reduction measures, however, will not by themselves offer a long-run solution to our problems. It is easy enough to spend one's way into a predicament, but difficult to save one's way out of it. So at a second level some "productivity improvements" must be sought. For instance, Dr. Smith has 
suggested that teaching loads might be increased, with no damage to research excellence. If the time thus required were to be gained by a corresponding reduction in the costly academic bureaucracy which many senates have created, then (as Dr. Smith has himself remarked) there need be no diminution of research effort, and relations with the public and government in the matter of the problem of "access" would be notably improved. One could think of still other "productivity" measures, for instance those associated with "working smarter" to improve the quality of our teaching. Of course, there is always the caveat that faculty, staff and students may have to be persuaded to "buy in" to changes some of which may be distasteful and unwelcome.

There are good reasons, however, for believing that we may eventually have to move to a third level and engage in systematic restructuring of our institutional forms. At a minimum, I submit that the restructuring must free academic institutions from the downright system contradictions from which they are currently suffering. Models and structures of governance and management on which we have relied in the past will not serve in the future. If present organizational modes cannot be substantially reduced in complexity, an alternative may be to dissolve our large structures into smaller and less constrained forms. If so, we would only be reflecting much of what is happening all around us in the political sphere. Fission into more or less independent parts may be the eventual order of the day. At any rate, these are the fundamental kinds of issues that must be addressed.

\section{A Preferential Option For the Excellent?}

We are accustomed these days to hearing theologians talk about the "preferential option for the poor." In the midst of our other concerns, could we also think about a preferential option for the excellent? If there is anything we need, in our national, social and economic life, it surely is to make room for excellence. And excellence seems to demand both freedom and the spur of competition. It also entails the taking of risk and accepting the freedom to fail-phenomena which really do not characterize the contemporary Canadian university.

There is no point in my trying to improve upon the vigorous case which Professor James Gillies made (at the 1991 annual meeting of the CorporateHigher Education Forum) both about the critical importance of excellence and the challenge it poses to our universities. In line with his suggestions, one could hope that some university board somewhere could take the lead in seeking a way out of the constraints that exert such a constant downward tug towards mediocrity. One could do wonders, for instance, with a "Venture Fund" of $2 \%$ 
of a general operating budget, or even as little as $1.5 \%$-not as a contingency fund but as a resource to invigorate and handsomely reward good teaching or to aid star researchers, whether in pure or applied fields, to achieve some critical breakthroughs. If a board cannot obtain and secure the continuation of such a fund in the operating base, that fact, more than anything else, would illustrate in dramatic fashion the type of bind in which our institutions are caught and from which they must be released.

The ultimate answer, of course, may be to follow up on Gillies' suggestion to "privatize" some key faculties and let them compete openly in the drive for excellence. No doubt there are obstacles in the way of a proposal of this kind, but the tonic effect of a few such examples would be of immense significance. If that particular avenue is blocked, then I would urge that energies should be devoted to finding some alternative route to an equivalent goal. If we are to become competitive as a nation, as so many voices are now urging, surely one of our first and most urgent tasks must be to free some critical sectors of the university world to become truly and fully competitive.

\section{Agenda For Renewal}

In considering possible responses to the predicament in which universities currently find themselves, two options must in my judgment be rejected. One is the view that the difficulties we are experiencing, while undoubtedly troublesome, are really not deep-rooted, and hence that all we need do is patiently await the return of sunny days and comfortable budgets. Some observers may indeed opt for such an analysis: for my part, I read the entrails in a quite different manner. A second alternative, which I also reject, is the stance of pessimism, viz., the position that nothing can be done to remedy our condition. Believing as I do that the university has been and must remain one of the axial institutions of modern civilization, I take it as axiomatic that our institutions have to escape from the straitened condition in which they currently find themselves. Given (secondly) that the federal government and even the wealthiest of our provinces are all running substantial deficits, with no relief yet in sight, I take it as a further axiom that our universities are not likely to be rescued at any time in the near future by floods of new financial resources. At the outset of these remarks, however, I was careful to point out that by no means all resources are of a financial nature. When it comes to the question of a supply of talent, expertise, knowledge, and inventiveness, universities are clearly far from bankrupt. The challenge now confronting them is to harness such resources to address in a serious and methodical way not only the fascinating issues at the frontiers of the 
disparate disciplines, where our successes have been very real, but also the structural problems which the institutions as such are facing. Such a shift in emphasis will admittedly be difficult but, in the words of the philosopher William James, it is surely a "forced option." As I have already observed, even within existing governance and management frameworks, much could in principle be done to stimulate the growth of more intensive modes of cost-consciousness and to achieve a significant enhancement of productivity.

However, I believe that even further measures may well be required, in the direction of re-thinking and re-structuring the organizational forms in which we have become accustomed to conduct our affairs. There is a fundamental dissonance between those forms and the realities in which universities are now embedded. The challenge we face is to invent new paradigms of participation and new models of governance to replace the overly complex and overburdened mechanisms that we have inherited from a very different past, a past that is gone beyond recall. Such a task of restructuring will call for some tough-minded thinking and will be far from painless. The primary onus for diagnosing the problem and formulating the appropriate responses surely rests upon the institutions themselves. However, the magnitude of the challenge is such that nothing can be achieved without responsiveness on the part of government and readiness to meet genuine proposals for restructuring at least half way. The distrust which currently appears to exist between the two parties has to be attacked from both sides, not one only. Moreover, success will also require the active interest and enlightened support of external stakeholders in the university enterprise. Without such a concerted response, the situation of the academy is only too likely to escalate from a mere "predicament" to a veritable "crisis." That is an outcome which we surely cannot afford.

\section{Notes:}

1 An earlier draft of this paper was prepared as a background study for the annual meeting of the Corporate-Higher Education Forum in Montreal in May, 1992.

2 References are to the proceedings of the National Conference of Canadian Universities, for 1927,1930 and 1932.

3 Of necessity, in a discussion of this brevity one has to operate from a composite and therefore fuzzy image of "the contemporary university." On the whole, I am tilting the image more towards what I take to be the problems typical of the large "multiversity," rather than to those of our smaller institutions.

4 Another concern, not mentioned in this paragraph, has to do with the matter of rethinking relationships between our colleges and our universities. In several provinces this question has apparently come to the forefront. Even where, as in Alberta, the basic 
structures were well-designed, tensions between the two sectors are now being induced by reason of the fact that universities have recently had to limit accessibility. This move creates a genuine dilemma. If universities do not "keep the bargain" with the college system, the entire enterprise falls apart. On the other hand, if they do keep the bargain, so that students with adequate or better performance in university transfer programs in the colleges have an unquestioned right to enter university, the resultant pressures may force universities to raise admission levels for students coming directly from high schools to undesirable or even unacceptable levels. In the face of this dilemma, some of the larger colleges are pressing vigorously for full degree-granting status. The effects on the system of higher education in the province if such a course were to be accepted are by no means clear, but given the likelihood of severe funding restrictions, they could be very significant and most unwelcome to the university sector.

5 In the formative years of our universitics, a body such as the academic senate clearly had an essential role to play. Any university history dealing with that period makes this fact very plain. The institution sought not only to realize some version of "the Idea of a university;" that general idea had necessarily to be given concrete embodiment under local or provincial circumstances and context. There truly was some "vision" or ethos which informed and directed such efforts, and which conferred upon each of them a particular "Idea" or identity. Saskatchewan was not Alberta and not Manitoba; Queen's was not Western; Mount Allison was not Acadia, and so on. As universities have become more and more alike, that distinctive identity has inevitably weakened. Under these changed conditions, the role of the senate becomes much more tenuous and problematic. The business of the university is conducted in innumerable departmental councils, faculty councils, deans' councils, administrative councils, board councils, and their plethora of committees and subcommittees. After all that analysis, just what further task is still left for senates? One might still hope for large "vision" to empower creative change in truly fundamental matters, but any such change requires an immense store of energy. In the contemporary university, distracted as it is by so many conflicting pressures, is the necessary energy really available?

6 It is difficult to draw any hard and fast distinctions between "governance" and "management." On the whole, we might think of structures of "governance" as those laid down in the constitution of the university, as spelled out in some charter or legislative act; and "management" as related to specilic structures established by boards of governors. However, the distinction is not absolutc. In Alberta, for instance, a collective bargaining regime is enshrined in the Universities Act itself. Elsewhere, such regimes are established by negotiations involving "management."

7 Anyone who espouses the maxims of Mr. Micawber (or, to keep our references gender-neutral, those of Pollyanna) might profitably read the most dismaying Research Report No. 5, developed for the Smith Commission. This study purports to reveal the attitudes and beliefs of ministers of advanced education and their professional staffs about a number of features of the university landscape. Some of their skepticism about the way in which universities manage their affairs is no doubt justified. In some cases, however, there seem to be the most alarming misconceptions or misperceptions.

For instance, there are complaints as to a serious lack of information about how universities spend the funds they receive. "Provincial governments," the report states, "do 
not feel they have sufficient information about how universities currently spend government funds, nor do they feel that universities make an adequate case for funding increases." It is further declared that this response was "uniformly negative." In the case of at least one province it is stated "that there were no figures on how individual institutions were spending their public funds.... The information provided was largely anecdotal."

I cannot generalize for all of Canada, but in every western university, governed as we all are by special university acts, it is perfectly clear that governments can demand any information they choose to require, and indeed they do so. Typically, we are required to submit specific information of a variety of kinds on forms approved by some governmental agency. Our budget books, our voluminous institutional "fact books," our audited financial returns, and so forth, are all filed with government. Veritable mountains of data about all universities in Canada are processed annually by such organizations as CAUBO (the Canadian Association of University Business Officers) and by Statistics Canada, not to mention those required and published by intermediary bodies or university collectives in several regions, such as Ontario, Quebec, and the Maritimes, or by bodies such as AUCC and various national councils. In short, it is difficult to accept this charge as having any general validity whatsoever.

According to this report there was also "virtual unanimity" among the respondents that universities are "out of sync with the needs of their communities," that they put inadequate priority on undergraduate education, that they have not done nearly enough to tap outside sources of funds, that they must be "more accountable" for what they spend, etc. However, governments appeared to have litte notion of just what performance indicators would be relevant and important. Despite this serious limitation, most respondents nevertheless "also saw a clear role for governments in encouraging, if not forcing, the streamlining process through the power of the public purse."

Altogether, if this study truly conveys an accurate assessment of current governmental opinion about universities, its implications are cause for considerable despondency. Yet if universities attempt to clarify their fiscal situation by proffering their own figures and analyses, they then fall under the suspicion of colouring the presentation by their own self-interest-as the report in question also seems to be suggesting. This is a lose-lose situation. The paramount impression left by this Report is of an attitude of profound distrust on the part of government towards universities.

8 If by "strategic planning" one has in mind the rather heroic version of planning advocated by George Keller, in his influential book, Academic Strategy, few if any instances of it are available in Canada. Although there is much talk about the limitations of "horizontal" or across the board budgetary cutting, and considerable theoretical commendation of such an option as the "vertical" excision of an entire unit, in practice thus far there seem to be remarkably few if any examples of cuts of truly significant or "strategic" dimensions. I can think of only one case in my experience, but the faculty in question was in academically weak condition, had no strong base of academic support, and in the end the most important part of it was saved-by transfer to another faculty. There have been some dramatic attempts along such lines in Ontario, but none as yet (so I understand) that have been successfully carried through at a massive or "strategic" level. An excellent empirical study of over 250 institutions in the United States revealed little success in the field of truly strategic planning endeavours. (See the report on 


\section{W.M. Sibley}

"College and University Planning," by Frank A. Schmidtlein and Toby H. Milton, in Planning for Higher Education, 17(3), 1988-89). It should be noted here that Keller gives as one of his indispensable conditions of strategic planning the seizure of commanding decision heights by some "big decision committee." When decision-making is widely diffused, however, such a necessary condition is unlikely to be realized. 